(unpublished data). Furthermore, invasive ventilation does not limit the use of electrically powered wheelchairs [10].

MARKSTRÖM et al. [11] observed a better quality of life in tracheostomised neuromuscular patients. However, this is contested by BACH [12]. In accordance with MARKSTRÖM et al. [11], and although our tracheostomised Duchenne muscular dystrophy (DMD) patients were more severe than our DMD patients under NIMV, quality of life was similar in both groups [13]. We trained families to perform airway suctioning and to change tracheostomy in order to allow them to face anxiety over airway occlusion.

Therefore, in these conditions, tracheostomy may avoid, rather than facilitate, institutionalisation for some patients and we consider that it is dangerous to state that there is no indication that tracheostomy is effective in DMD patients. Each case has to be considered on its merits, without any dogma.

We would like to thank the editors for allowing us to extend this important debate about tracheostomy in neuromuscular patients which underlines that the team's experience and expertise is an important determinant of the choice of the time to switch to tracheostomy.

\section{F. Lofaso ${ }^{*, \#}$, D. Orlikowski* and J-C. Raphael*}

*Intensive Care Unit and Dept of Physiology-Functional Testing and Centre for Technological Innovation, Raymond Poincaré Teaching Hospital, Garches, and "Inserm UMR 651, Créteil, France.

\section{STATEMENT OF INTEREST}

None declared.

\section{REFERENCES}

1 Trebbia G, Lacombe M, Fermanian C, et al. Cough determinants in patients with neuromuscular disease. Respir Physiol Neurobiol 2005; 146: 291-300.

2 Toussaint M, Steens M, Wasteels G, Soudon P. Diurnal ventilation via mouthpiece: survival in end-stage Duchenne patients. Eur Respir J 2006; 28: 549-555.
3 American Thoracic Society/European Respiratory Society, ATS/ERS Statement on respiratory muscle testing. Am J Respir Crit Care Med 2002; 166: 518-624.

4 Orlikowski D, Prigent H, Gonzalez-Bermejo J, et al. Noninvasive ventilation as alternative to endotracheal intubation for tracheostomy in advanced neuromuscular disease. Respir Care 2007 (in revision).

5 Chadda K, Louis B, Benaissa L, et al. Physiological effects of decannulation in tracheostomized patients. Intensive Care Med 2002; 28: 1761-1767.

6 Prigent $\mathrm{H}$, Orlikowski D, Blumen MB, et al. Characteristics of tracheostomy phonation valves. Eur Respir J 2006; 27: 992-996.

7 Vassilakopoulos T, Petrof BJ. Ventilator-induced diaphragmatic dysfunction. Am J Respir Crit Care Med 2004; 169: 336-341.

8 Prigent H, Samuel C, Louis B, et al. Comparative effects of two ventilatory modes on speech in tracheostomized patients with neuromuscular disease. Am J Respir Crit Care Med 2003; 167: 114-119.

9 Terzi N, Orlikowski D, Aegerter P, et al. Breathingswallowing interaction in neuromuscular patients: a physiological evaluation. Am J Respir Crit Care Med 2007; 175: 269-276.

10 Pellegrini N, Guillon B, Prigent H, et al. Optimization of power wheelchair control for patients with severe Duchenne muscular dystrophy. Neuromuscul Disord 2004; 14: 297-300.

11 Markström A, Sundell K, Lysdahl M, Andersson G, Schedin U, Klang B. Quality-of-life evaluation of patients with neuromuscular and skeletal diseases treated with noninvasive and invasive home mechanical ventilation. Chest 2002; 122: 1695-1700.

12 Bach JR. Noninvasive ventilation is more than mask ventilation. Chest 2003; 123: 2156-2157.

13 Raphael JC, Dazord A, Jaillard P, et al. Indices de satisfaction des patients atteints d'une dystrophie musculaire de Duchenne de Boulogne et ventilés à domicile. [Assessment of quality of life for home ventilated patients with Duchenne muscular dystrophy.] Rev Neurol (Paris) 2002; 158: 453-460.

DOI: $10.1183 / 09031936.00027307$

\title{
Exercise recovery phase: unrecovered part of the recommendations
}

\section{To the Editors:}

As the implications of cardiopulmonary exercise testing (CPET) are continually growing, PALANGE et al. [1] are to be congratulated for their paper entitled "Recommendations on use of exercise testing in clinical practice". It has been long awaited, as extensive research in the area simply outdated previous European [2] and American guidelines [3]. As PALANGE et al. [1] mentioned that assessment requires integrative interpretation of a "cluster of response variables", it seemed surprising that no parameter describing the recovery period was discussed.

We would like to highlight the recovery period as an integral part of CPET, which is important for the sufficiency of data [2]. Although on- and off-kinetics are in close relation, they are not always symmetrical, due to altered tissue metabolism after exercise, which alone is a strong argument for incorporating 
recovery data in CPET analysis [4]. The presence of such a discrepancy would be beneficial for further restratification of patients.

Nevertheless, a correlation between parameters during exercise and recovery is present in most cases. As summarised in the American College of Cardiology/American Heart Association Guidelines [3], impaired oxygen uptake $\left(V^{\prime} \mathrm{O}_{2}\right)$ kinetics during recovery correlate strongly with exercise tolerance, peak $V^{\prime} \mathrm{O}_{2}$ $\left(V^{\prime} \mathrm{O}_{2}\right.$,peak) and cardiac index in congestive heart failure $(\mathrm{CHF})$ patients. Diagnostic and prognostic importance have been well demonstrated for several parameters, namely $V^{\prime} \mathrm{O}_{2}$ kinetics [3], heart rate recovery (HRR) [3,5], blood pressure response [3], ventricular ectopy [6] and ST changes from exercise recovery [3], in various diseases including $\mathrm{CHF}$ and chronic obstructive pulmonary disease. Information from the exercise recovery phase could support the interpretation of CPET results from submaximal exercise where poor effort or malingering are suspected.

Except for objective measurements during CPET, additional valuable information is gained from the continuous monitoring of patients' symptoms [7]. We believe that the dynamics of symptoms during the recovery period provides supplementary information about functional severity of diseases and worsened quality of life.

The sensitivity of the recovery phase to training, traditionally applied in the assessment of athletes' training programmes and recently documented in several state-of-the-art publications $[4,8]$, implies a possible use in the evaluation of various exercise training programmes.

The main recovery period parameters $\left(V^{\prime} \mathrm{O}_{2}\right.$, carbon dioxide production and minute ventilation) fit exponential decay curves and are, therefore, best described by means of timedelays and time-constants; these demand mathematical analysis and, consequently, are not easy to apply in every-day practice. Fortunately, several simple derivatives exist, including $\mathrm{HRR}, V^{\prime} \mathrm{O}_{2}$,peak $/ V^{\prime} \mathrm{O}_{2}$ recovery at the 5 th minute, time to reach $50 \%$ of $V^{\prime} \mathrm{O}_{2}$,peak and respiratory exchange ratio dynamics, and have been proven to be informative $[3,5,9,10]$.

On careful analysis of the literature and our own experience, we believe that even though accessory, recovery parameters (including dynamics of symptoms) are quite informative and should be considered in the evaluation of CPET results, especially in patients prevented from achieving maximal effort criteria, those in rehabilitation programmes and for precise patient restratification.

We are eager to initiate discussion on the utility of the exercise recovery phase in different exercise tests.

\section{S. Kostianev, K. Terziyski and B. Marinov}

Dept of Pathophysiology, Medical University of Plovdiv, Plovdiv, Bulgaria.

\section{STATEMENT OF INTEREST}

None declared.

\section{REFERENCES}

1 Palange $\mathrm{P}$, Ward SA, Carlsen $\mathrm{K}-\mathrm{H}$, et al. Recommendations on the use of exercise testing in clinical practice. Eur Respir J 2007; 29: 185-209.

2 ERS Clinical exercise testing with reference to lung diseases, indications, standardization and interpretation strategies. Task Force on Standardization of Clinical Exercise Testing. European Respiratory Society. Eur Respir J 1997; 10: 2662-2689.

3 Gibbons RJ, Balady GJ, Bricker JT, et al. ACC/AHA 2002 guideline update for exercise testing: summary article. A report of the American College of Cardiology/American Heart Association Task Force on Practice Guidelines (Committee to Update the 1997 Exercise Testing Guidelines). J Am Coll Cardiol 2002; 40:1531-1540.

4 Perrey S, Candau R, Borrani F, Millet GY, Rouillon JD. Recovery kinetics of oxygen uptake following severeintensity exercise in runners. J Sports Med Phys Fitness 2002; 42: 381-388.

5 Lacasse M, Maltais F, Poirier P, et al. Post-exercise heart rate recovery and mortality in chronic obstructive pulmonary disease. Respir Med 2005; 99: 877-886.

6 Lauer M, Froelicher ES, Williams M, Kligfield P, American Heart Association Council on Clinical Cardiology, Subcommittee on Exercise, Cardiac Rehabilitation, and Prevention. Exercise testing in asymptomatic adults: a statement for professionals from the American Heart Association Council on Clinical Cardiology, Subcommittee on Exercise, Cardiac Rehabilitation, and Prevention. Circulation 2005; 112: 771-776.

7 Task Force of the Italian Working Group on Cardiac Rehabilitation and Prevention (Gruppo Italiano di Cardiologia Riabilitativa e Prevenzione, GICR), Working Group on Cardiac Rehabilitation and Exercise Physiology of the European Society of Cardiology. Statement on cardiopulmonary exercise testing in chronic heart failure due to left ventricular dysfunction: recommendations for performance and interpretation Part III: Interpretation of cardiopulmonary exercise testing in chronic heart failure and future applications. Eur J Cardiovasc Prev Rehabil 2006; 13: 485-494.

8 Streuber SD, Amsterdam EA, Stebbins CL. Heart rate recovery in heart failure patients after a 12-week cardiac rehabilitation program. Am J Cardiol 2006; 97: 694-698.

9 Tokmakova M, Kostianev S, Dobreva B, Djurdjev A. Diagnostic value of parameters from the recovery phase of cardiopulmonary exercise test in patients with chronic heart failure. Bulgarian Cardiology 1999; 2: 34-41.

10 Queiros MC, Mendes DE, Ribeiro MA, Mendes M, Rebocho MJ, Seabra-Gomes R. Recovery kinetics of oxygen uptake after cardiopulmonary exercise test and prognosis in patients with left ventricular dysfunction. Rev Port Cardiol 2002; 21: 383-398.

DOI: $10.1183 / 09031936.00016707$

\section{From the authors:}

We thank S. Kostianev and co-workers for their comments relating to the recent European Respiratory Society Task Force document [1]. In contrast to the attention given to the utility of 